\title{
Instantaneous Active and Reactive Power and Current Strategies for Current Harmonics Cancellation in 3-ph 4-Wire SHAF with Both PI and Fuzzy Controllers
}

\author{
Suresh Mikkili, Anup Kumar Panda \\ Department of Electrical Engineering, National Institute of Technology, Rourkela, India \\ E-mail: \{msuresh.ee, akpanda.ee\}@gmail.com \\ Received February 25, 2011; revised March 22, 2011; accepted April 11, 2011
}

\begin{abstract}
Control strategies for extracting the three-phase reference currents for shunt active power filters are compared, evaluating their performance under different source conditions with PI and Fuzzy Controllers in MATLAB/Simulink environment When the supply voltages are balanced and sinusoidal, the two control strategies are converge to the same compensation characteristics; However, the supply voltages are distorted and/or un-balanced sinusoidal, these control strategies result in different degrees of compensation in harmonics. The compensation capabilities are not equivalent, with $p-q$ control strategy unable to yield an adequate solution when source voltages are not ideal. Extensive simulations are carried out with PI controller and also with Fuzzy controller for both $p-q$ and $i_{d}-i_{q}$ control strategies under different main voltages. Extensive Simulations are carried out with PI as well as fuzzy controller for both $p-q$ and $i_{d}-i_{q}$ control strategies by considering different voltage conditions and adequate results were presented. On owing $i_{d}-i_{q}$ method with fuzzy logic controller gives away an out-standing performance under any voltage conditions (balanced, un-balanced, balanced and non-sinusoidal).
\end{abstract}

Keywords: Harmonic Compensation, Shunt Active Filter (SHAF), $p-q$ Control Strategy, $i_{d}-i_{q}$ Control Strategy, PI Controller and Fuzzy Controller

\section{Introduction}

The power-electronic-based loads such as adjustable speed drives, rectifier equipment used in telecommunication networks, power supplies, domestic appliances, etc offer highly nonlinear characteristics. These nonlinear loads draw non-sinusoidal [1] currents from ac mains and cause reactive power burden and excessive neutral current. They are also responsible for lower efficiency and interference of distribution system with the nearby communication networks. To improve the efficiency, capacitors are employed which also leads to the improvement of power factor of the mains. On the other hand, to reduce the interference with the communication network due to harmonics in the current flowing in the distribution system, passive-filters are used. But they have the limitations of fixed compensation, large size, and that they can create new system resonance.

Present work mainly focused on two control strategies $p-q$ and $i_{d}-i_{q}$ by using two controllers i.e., fuzzy [2] and PI. Instantaneous active and reactive theory ( $p-q$ theory) was introduced by H. Akagi, kawakawa, and Nabae in 1984. Since then, many scientists and engineers made significant contributions to its modifications in threephase four-wire circuits and its applications to power electronic equipment. The $p-q$ theory [3] based on a set of instantaneous powers defined in the time domain. No restrictions are imposed on the voltage and current waveforms, and it can be applied to three phase systems with or without neutral wire for three phase generic voltage and current waveforms. Thus it is valid not only in the steady state but also in the transient state. $p-q$ theory needs additional PLL circuit for synchronization so $p-q$ method is frequency variant.

In $i_{d}-i_{q}$ method [4] angle " $\theta$ " is calculated directly from main voltages and thus enables the method to be frequency independent. Thus large numbers of synchronization problems with un-balanced and non-sinusoidal voltages are also avoided.

The PI controller [5] requires precise linear mathematical models, which are difficult to obtain and may not give satisfactory performance under parameter variations, 
load disturbances, etc. Recently, fuzzy logic controllers have received a great deal of interests in APF. The advantages of fuzzy controllers over conventional controllers are that they do not need an accurate mathematical model, can work with imprecise inputs, can handle non-linearity, and are more robust than conventional controllers. The Mamdani type of fuzzy controller [6] used for the control of APF gives better results compared with the PI controller, but it has the drawback of a larger number of fuzzy sets and 49 rules. This increases the complexity of the controller; hence, this demands large computational time. As a result, it may not be useful for real-time applications with small sampling time.

When the supply voltages are balanced and sinusoidal, both $p-q$ and $i_{d}-i_{q}$ control strategies are converge to the same compensation characteristics but when the supply voltages are distorted and/or un-balanced sinusoidal, these control strategies result in different degrees of compensation in harmonics. The $p-q$ control strategy is unable to yield an adequate solution when source voltages are not ideal. PI controller fails to respond quickly because of non-linear nature in the system, so we are developing soft computing techniques to analyze the performance of system under distorted condition. Fuzzy supports with outstanding performance under any voltage conditions. On observing $i_{d}-i_{q}$ method with fuzzy logic controller gives away an out-standing performance under any voltage conditions.

\section{Shunt Active Filter Configuration}

To employ APFs in three-phase four-wire systems, two types of configurations are possible; one is a three-leg structure with the neutral conductor being connected to midpoint of dc-link capacitor (Figure 1); and the other one is a four-leg structure, where a fourth leg is provided exclusively for neutral current compensation (Figure 2). Despite the fact, this topology is seldom preferred owing to less number of switching devices and lower switching losses compared to the eight-switch topology [7]. However, the higher order harmonics generated in the eight switch configuration due to frequent switching of semiconductor devices can be eliminated by the use of RC high-pass filter as shown in Figure 2 and switching losses occurring in the VSI can also be minimized by the use of DC-link voltage regulator [8]. Moreover, the fourleg APF has simple dc-link voltage controller, requires small dc-link capacitor, and the control scheme is also quite simple to implement.

The four-leg eight-switch APF topology is preferred to be implemented as many researchers have appointed this configuration as the most proficient alternative to be used in shunt APF [8]. The three-leg six-switch split-

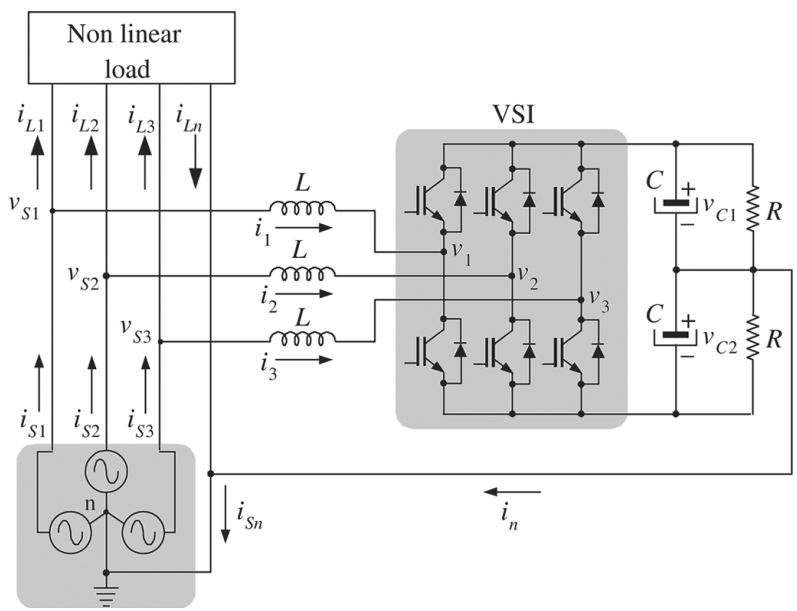

Figure 1. Three-leg shunt APF with non-linear load.

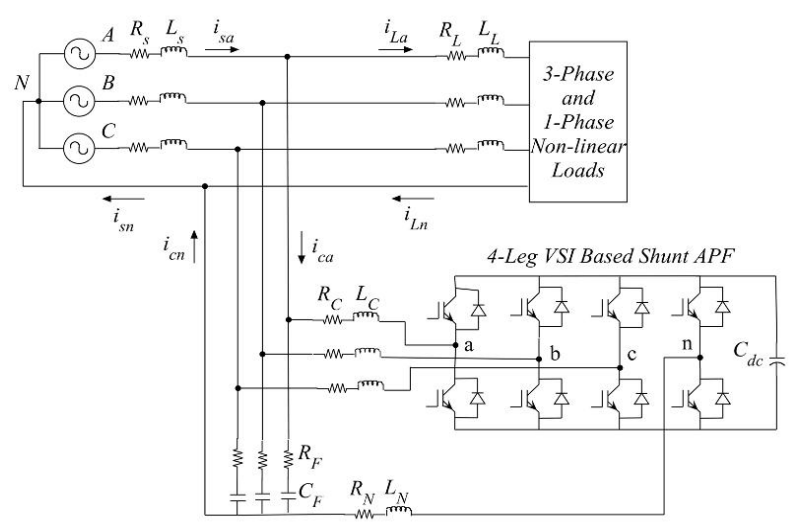

Figure 2. Four-leg shunt APF with non-linear load.

capacitor configuration of shunt APF suffers from several shortcomings viz.

1) Control circuit is somewhat complex;

2) Voltages of the two capacitors of split-capacitor need to be properly balanced;

3) Large dc-link capacitors are required.

\section{Instantaneous Active and Reactive Power $(p-q)$ Method}

The control algorithm block diagram for $p-q$ method is depicted in Figure 3. The three-phase source voltages $\left(v_{\mathrm{s} a}, v_{\mathrm{s} b}, v_{\mathrm{sc}}\right)$ and load currents $\left(i_{L a}, i_{L b}, i_{L c}\right)$ in the $a-b-c$ coordinates are algebraically transformed to the $\alpha-\beta$ coordinates using Clarke's transformation as per (1) and (2), followed by the calculation of the instantaneous active power $(p)$ and reactive power $(q)$ by following (3).

$$
\left[\begin{array}{l}
V_{\alpha} \\
V_{\beta}
\end{array}\right]=\sqrt{\frac{2}{3}}\left[\begin{array}{ccc}
1 & \frac{1}{2} & \frac{1}{2} \\
0 & \frac{\sqrt{3}}{2} & -\frac{\sqrt{3}}{2}
\end{array}\right]\left[\begin{array}{l}
v_{a} \\
v_{b} \\
v_{c}
\end{array}\right]
$$




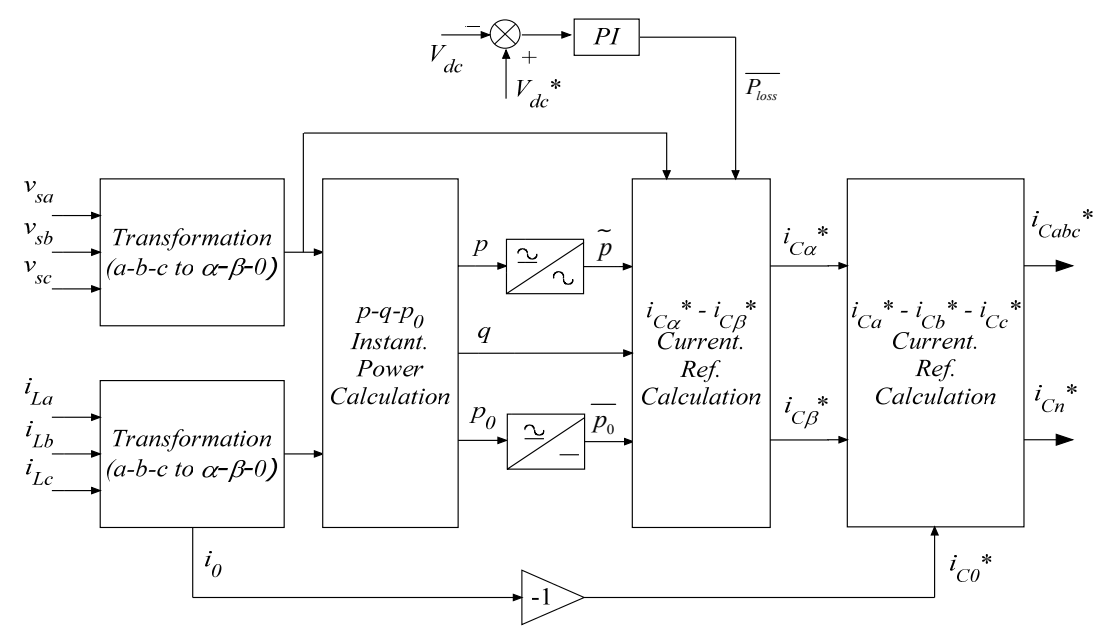

Figure 3. Reference current extraction with conventional $p$-q method.

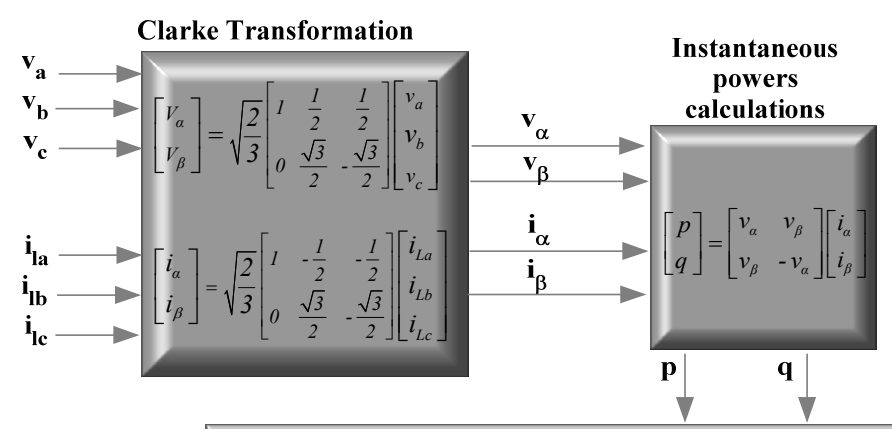

Selection of the powers to be compensated

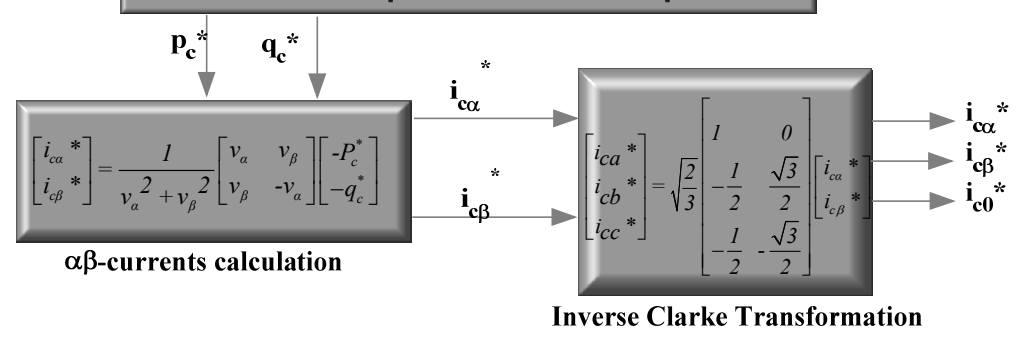

Figure 4. Control method for Shunt current compensation based on $p$ - $q$ theory.

$$
\begin{gathered}
{\left[\begin{array}{c}
i_{\alpha} \\
i_{\beta}
\end{array}\right]=\sqrt{\frac{2}{3}}\left[\begin{array}{ccc}
1 & -\frac{1}{2} & -\frac{1}{2} \\
0 & \frac{\sqrt{3}}{2} & -\frac{\sqrt{3}}{2}
\end{array}\right]\left[\begin{array}{l}
i_{L a} \\
i_{L b} \\
i_{L c}
\end{array}\right]} \\
{\left[\begin{array}{l}
p \\
q
\end{array}\right]=\left[\begin{array}{cc}
v_{\alpha} & v_{\beta} \\
v_{\beta} & -v_{\alpha}
\end{array}\right]\left[\begin{array}{l}
i_{\alpha} \\
i_{\beta}
\end{array}\right]}
\end{gathered}
$$

Each of these powers has dc component (1st component) and ac component (2nd component) as shown in (4).

$$
\begin{aligned}
& p=\bar{p}+\tilde{p} \\
& q=\bar{q}+\tilde{q}
\end{aligned}
$$

For reactive and harmonic compensation, the entire reactive power and ac component of active power are utilized as the reference power. The reference currents in $\alpha-\beta$ coordinates are calculated by using (5) (Figure 4).

$$
\left[\begin{array}{l}
i_{c \alpha}^{*} \\
i_{c \beta}^{*}
\end{array}\right]=\frac{1}{v_{\alpha}^{2}+v_{\beta}^{2}}\left[\begin{array}{cc}
v_{\alpha} & v_{\beta} \\
v_{\beta} & -v_{\alpha}
\end{array}\right]\left[\begin{array}{l}
-P_{c}^{*} \\
-q_{c}^{*}
\end{array}\right]
$$

$$
\left[\begin{array}{l}
i_{c a}^{*} \\
i_{c b}^{*} \\
i_{c c}^{*}
\end{array}\right]=\sqrt{\frac{2}{3}}\left[\begin{array}{cc}
1 & 0 \\
-\frac{1}{2} & \frac{\sqrt{3}}{2} \\
-\frac{1}{2} & -\frac{\sqrt{3}}{2}
\end{array}\right]\left[\begin{array}{l}
i_{c \alpha}^{*} \\
i_{c \beta}^{*}
\end{array}\right]
$$

In addition PLL (Phase locked loop) employed in 
shunt filter tracks automatically, the system frequency and fundamental positive-sequence component of three phase generic input signal. Appropriate design of PLL allows proper operation under distorted and unbalanced voltage conditions. Controller includes small changes in positive sequence detector as harmonic compensation is mainly concentrated on three phase four wire [9]. As we know in three-phase three wire, $v_{a}^{\prime}, v_{b}^{\prime}, v_{c}^{\prime}$ are used in transformations which resemble absence of zero sequence component and it is given in Equation (7). Thus in three phase four wire it was modified as $v_{\alpha}^{\prime}, v_{\beta}^{\prime}$ and it is given in Equation (8).

$$
\begin{gathered}
{\left[\begin{array}{l}
v_{a}^{\prime} \\
v_{b}^{\prime} \\
v_{c}^{\prime}
\end{array}\right]=\sqrt{\frac{2}{3}}\left[\begin{array}{cc}
1 & 0 \\
-\frac{1}{2} & \frac{\sqrt{3}}{2} \\
-\frac{1}{2} & -\frac{\sqrt{3}}{2}
\end{array}\right]\left[\begin{array}{c}
v_{\alpha}^{\prime} \\
v_{\beta}^{\prime}
\end{array}\right]} \\
{\left[\begin{array}{l}
v_{\alpha}^{\prime} \\
v_{\beta}^{\prime}
\end{array}\right]=\frac{1}{i_{\alpha}^{\prime 2}+i_{\beta}^{\prime 2}}\left[\begin{array}{cc}
i_{\alpha}^{\prime} & -i_{\beta}^{\prime} \\
i_{\beta}^{\prime} & i_{\alpha}^{\prime}
\end{array}\right]\left[\begin{array}{l}
\bar{p}^{\prime} \\
\bar{q}^{\prime}
\end{array}\right]}
\end{gathered}
$$

\section{Instantaneous Active and Reactive Current Method $\left(i_{d}-i_{q}\right)$}

In Figure 5, the entire reference current generation scheme has been illustrated. The load currents $i_{L a}, i_{L b}$ and $i_{L c}$ are tracked upon which Park's transformation is performed to obtain corresponding $d-q$ axes currents $i_{L d}$ and $i_{L q}$ as given in (9), where $\omega$ is rotational speed of synchronously rotating $d-q$ frame. According to $i_{d}-i_{q}$ control strategy, only the average value of $d$-axis component of load current should be drawn from supply. Here $i_{L d l h}$ and $i_{L q 1 h}$ indicate the fundamental frequency component of $i_{L d}$ and $i_{L q}$. The oscillating components $i_{L d}$ and $i_{L q}$, i.e., $i_{L d n h}$ and $i_{\text {Lqnh }}$ are filtered out using low-pass filter.

$$
\begin{aligned}
& {\left[\begin{array}{l}
i_{L d} \\
i_{L q}
\end{array}\right]=\left[\begin{array}{l}
i_{L d 1 h}+i_{L d n h} \\
i_{L q i h}+i_{L q n h}
\end{array}\right]} \\
& {\left[\begin{array}{l}
i_{L d} \\
i_{L q}
\end{array}\right]=\left[\begin{array}{cc}
\sin w t & \cos w t \\
-\cos w t & -\sin w t
\end{array}\right]\left[\begin{array}{ccc}
1 & -1 / 2 & -1 / 2 \\
0 & \sqrt{3} / 2 & -\sqrt{3} / 2
\end{array}\right]\left[\begin{array}{l}
i_{L a} \\
i_{L b} \\
i_{L c}
\end{array}\right]}
\end{aligned}
$$

The currents $i_{L d n h}$ and $i_{L q n h}$ along with $i_{d l h}$ are utilized to generate reference filter currents $i_{c d}{ }^{*}$ and $i_{c q} *$ in $d-q$ coordinates, followed by inverse Park transformation giving away the compensation currents $i_{c a}{ }^{*}, i_{c b}{ }^{*}, i_{c c}{ }^{*}$ and $i_{c n} *$ in the four wires as described in (10) and (11).

$$
\begin{gathered}
{\left[\begin{array}{l}
i_{c a}^{*} \\
i_{c b}^{*} \\
i_{c c}^{*}
\end{array}\right]=\left[\begin{array}{ccc}
\sin w t & \cos w t & 1 \\
\sin (w t-2 \pi / 3) & \cos (w t-2 \pi / 3) & 1 \\
\sin (w t+2 \pi / 3) & \cos (w t+2 \pi / 3) & 1
\end{array}\right]\left[\begin{array}{l}
i_{c d}^{*} \\
i_{c q}^{*} \\
i_{c 0}^{*}
\end{array}\right]} \\
i_{c n}^{*}=i_{c a}^{*}+i_{c b}^{*}+i_{c c}^{*}
\end{gathered}
$$

The reference signals thus obtained are compared with the actual compensating filter currents in a hysteresis comparator, where the actual current is forced to follow the reference and provides instantaneous compensation by the APF [10] on account of its easy implementation and quick prevail over fast current transitions. This consequently provides switching signals to trigger the IGBTs inside the inverter. Ultimately, the filter provides necessary compensation for harmonics in the source current and reactive power unbalance in the system. Figure 6 shows voltage and current vectors in stationary and rotating reference frames. The transformation angle ' $\theta$ ' is sensible to all voltage harmonics and unbalanced voltages; as a result $\mathrm{d} \theta / \mathrm{d} t$ may not be constant.

One of the advantages of this method is that angle $\theta$ is calculated directly from main voltages and thus makes this method frequency independent by avoiding the PLL in the control circuit. Consequently synchronizing prob

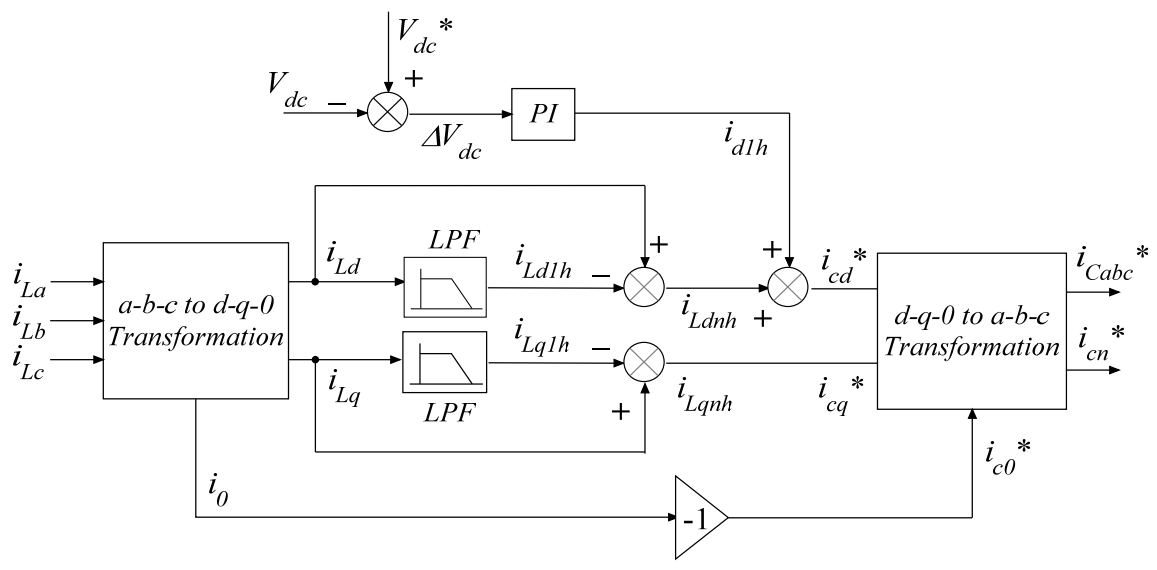

Figure 5. Reference current extraction with $i_{d}-i_{q}$ method. 


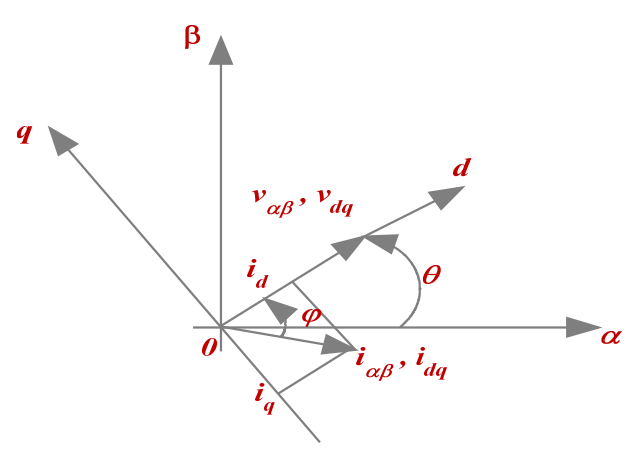

Figure 6. Instantaneous voltage and current vectors.

lems with unbalanced and distorted conditions of main voltages are also evaded. Thus $i_{d}-i_{q}$ achieves large frequency operating limit essentially by the cut-off frequency of voltage source inverter (VSI) [11].

Figures 5 and $\mathbf{6}$ show the control diagram for shunt active filter and harmonic injection circuit. On owing load currents $i_{d}$ and $i_{q}$ are obtained from park transformation then they are allowed to pass through the high pass filter to eliminate dc components in the nonlinear load currents. Filters used in the circuit are Butterworth type and to reduce the influence of high pass filter an alternative high pass filter (AHPF) can be used in the circuit. It can be obtained through the low pass filter (LPF) of same order and cut-off frequency simply difference between the input signal and the filtered one, which is clearly shown in Figure 5. Butterworth filters used in harmonic injecting circuit have cut-off frequency equal to one half of the main frequency $\left(f_{c}=f / 2\right)$, with this a small phase shift in harmonics and sufficiently high transient response can be obtained.

\section{Construction of PI Controller}

Figure 7 shows the internal structure of the control circuit. The control scheme consists of PI controller, limiter, and three phase sine wave generator for reference current generation and generation of switching signals [12]. The peak value of reference currents is estimated by regulating the DC link voltage. The actual capacitor voltage is compared with a set reference value.

The error signal is then processed through a PI controller, which contributes to zero steady error in tracking the reference current signal. The output of the PI controller is considered as peak value of the supply current $\left(I_{\max }\right)$, which is composed of two components: a) fundamental active power component of load current, and b) loss component of APF; to maintain the average capacitor voltage to a constant value. Peak value of the current $\left(I_{\max }\right)$ so obtained, is multiplied by the unit sine vectors in phase with the respective source voltages to obtain the

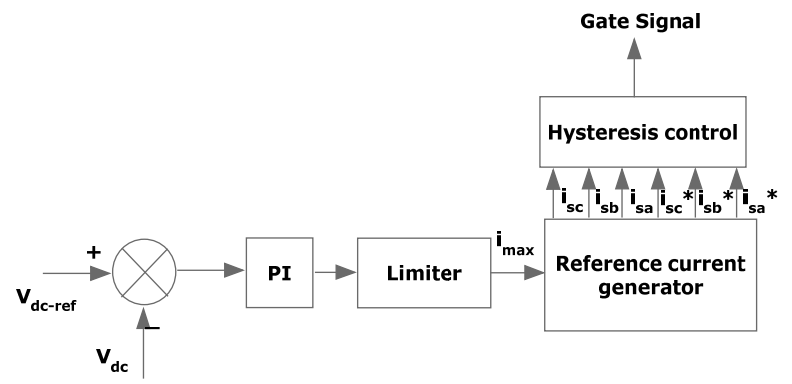

Figure 7. Conventional PI controller.

reference compensating currents. These estimated reference currents $\left(I_{s a}{ }^{*}, I_{s b}{ }^{*}, I_{s c}{ }^{*}\right)$ and sensed actual currents $\left(I_{s a}, I_{s b}, I_{s c}\right)$ are compared at a hysteresis band, which gives the error signal for the modulation technique. This error signal decides the operation of the converter switches. In this current control circuit configuration, the source/supply currents $I_{s a b c}$ are made to follow the sinusoidal reference current $I_{a b c}$, within a fixed hysteretic band. The width of hysteresis window determines the source current pattern, its harmonic spectrum and the switching frequency of the devices.

The DC link capacitor voltage is kept constant throughout the operating range of the converter. In this scheme, each phase of the converter is controlled independently. To increase the current of a particular phase, the lower switch of the converter associated with that particular phase is turned on while to decrease the current the upper switch of the respective converter phase is turned on. With this one can realize, potential and feasibility of PI controller.

\section{Construction of Fuzzy Controller}

Figure 8 shows the internal structure of the control circuit. The control scheme consists of Fuzzy controller, limiter, and three phase sine wave generator for reference current generation and generation of switching signals. The peak value of reference currents [13] is estimated by regulating the DC link voltage. The actual capacitor voltage is compared with a set reference value. The error signal is then processed through a Fuzzy controller, which contributes to zero steady error in tracking the reference current signal.

A fuzzy controller [14] converts a linguistic control strategy into an automatic control strategy, and fuzzy rules are constructed by expert experience or knowledge database. Firstly, input voltage $V_{d c}$ and the input reference voltage $V_{d c-r e f}$ have been placed of the angular velocity to be the input variables of the fuzzy logic controller. Then the output variable of the fuzzy logic controller is presented by the control Current $I_{\max }$. To convert these numerical variables into linguistic variables, the following seven fuzzy levels or sets are chosen as: 
NB (negative big), NM (negative medium), NS (negative small), ZE (zero), PS (positive small), PM (positive medium), and PB (positive big) as shown in Figure 9.

The fuzzy controller is characterized as follows:

1) Seven fuzzy sets for each input and output;

2) Fuzzification using continuous universe of discourse;

3) Implication using Mamdani's 'min' operator;

4) De-fuzzification using the 'centroid' method.

Fuzzification: the process of converting a numerical variable (real number) convert to a linguistic variable (fuzzy number) is called fuzzification.

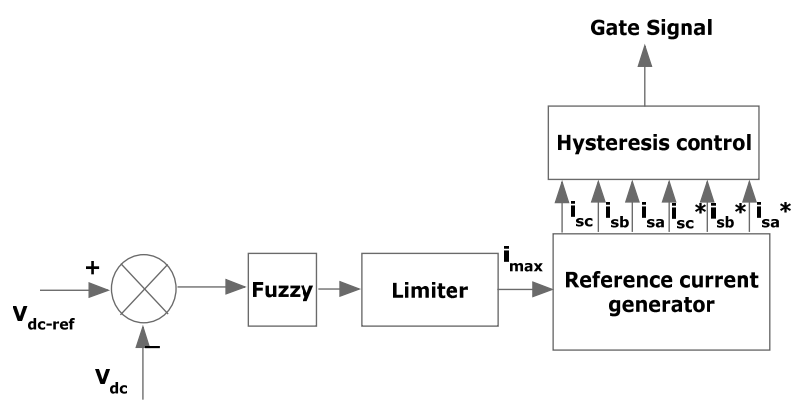

Figure 8. Conventional fuzzy controller.

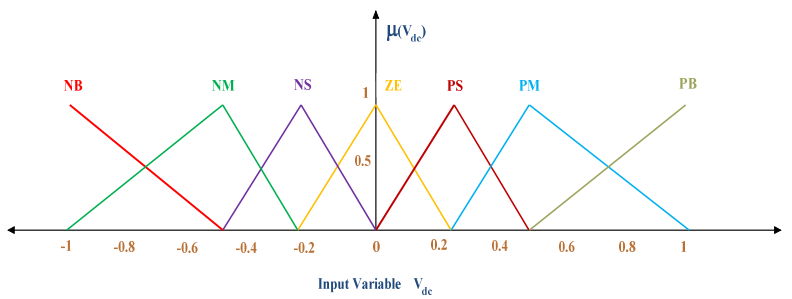

(a)

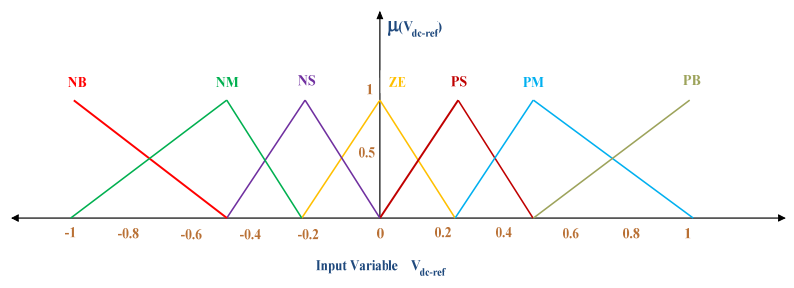

(b)

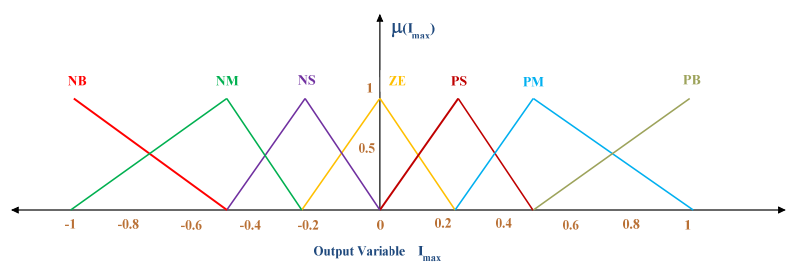

(c)

Figure 9. (a) Input $V_{d c}$ normalized membership function; (b) Input $V_{d c-r e f}$ Normalized Membership Function; (c) Output $I_{\max }$ Normalized Membership Function.
De-fuzzification: the rules of FLC generate required output in a linguistic variable (Fuzzy Number), according to real world requirements, linguistic variables have to be transformed to crisp output (Real number).

Database: the Database stores the definition of the membership Function required by fuzzifier and defuzzifier.

Rule Base: the elements of this rule base table are determined based on the theory that in the transient state, large errors need coarse control, which requires coarse input/output variables; in the steady state, small errors need fine control, which requires fine input/output variables. Based on this the elements of the rule table are obtained as shown in Table 1, with' $V_{d c}$ ' and ' $V_{d c-r e f}$ ' as inputs.

\section{Results and Discussions}

Figure 10, Figure 11 and Figure 12 illustrate the performance of shunt active power filter under different main voltages, as load is highly inductive, current draw by load is integrated with rich harmonics.

Figure 10 illustrates the performance of Shunt active power filter under balanced sinusoidal voltage condition. THD for $p-q$ method with PI controller is $2.15 \%$, THD for $p-q$ method with Fuzzy controller is $1.27 \%$, THD for $i_{d}-i_{q}$ method with PI controller is $1.97 \%$ and THD for $i_{d}-i_{q}$ method with Fuzzy Controller is $0.97 \%$.

Figure 11 illustrates the performance of Shunt active power filter under un-balanced sinusoidal voltage condition. THD for $p-q$ method with PI controller is $4.16 \%$, THD for $p-q$ method with Fuzzy controller is $2.98 \%$, THD for $i_{d}-i_{q}$ method with PI controller is $3.11 \%$ and THD for $i_{d}-i_{q}$ method with Fuzzy Controller is $1.64 \%$.

Figure 12 illustrates the performance of Shunt active power filter under balanced non-sinusoidal voltage condition. THD for $p-q$ method with PI controller is $5.31 \%$, THD for $p-q$ method with Fuzzy controller is $3.85 \%$, THD for $i_{d}-i_{q}$ method with PI controller is $4.92 \%$ and THD for $i_{d}-i_{q}$ method with Fuzzy Controller is 3.01\%.

Table 1. Rule base.

\begin{tabular}{cccccccc}
\hline$V_{\text {de-ref }}$ & $\mathrm{NB}$ & $\mathrm{NM}$ & $\mathrm{NS}$ & $\mathrm{Z}$ & $\mathrm{PS}$ & $\mathrm{PM}$ & $\mathrm{PB}$ \\
\hline $\mathrm{NB}$ & $\mathrm{NB}$ & $\mathrm{NB}$ & $\mathrm{NB}$ & $\mathrm{NB}$ & $\mathrm{NM}$ & $\mathrm{NS}$ & $\mathrm{Z}$ \\
$\mathrm{NM}$ & $\mathrm{NB}$ & $\mathrm{NB}$ & $\mathrm{NB}$ & $\mathrm{NM}$ & $\mathrm{NS}$ & $\mathrm{Z}$ & $\mathrm{PS}$ \\
$\mathrm{NS}$ & $\mathrm{NB}$ & $\mathrm{NB}$ & $\mathrm{NM}$ & $\mathrm{NS}$ & $\mathrm{Z}$ & $\mathrm{PS}$ & $\mathrm{PM}$ \\
$\mathrm{Z}$ & $\mathrm{NB}$ & $\mathrm{NM}$ & $\mathrm{NS}$ & $\mathrm{Z}$ & $\mathrm{PS}$ & $\mathrm{PM}$ & $\mathrm{PB}$ \\
$\mathrm{PS}$ & $\mathrm{NM}$ & $\mathrm{NS}$ & $\mathrm{Z}$ & $\mathrm{PS}$ & $\mathrm{PM}$ & $\mathrm{PB}$ & $\mathrm{PB}$ \\
$\mathrm{PM}$ & $\mathrm{NS}$ & $\mathrm{Z}$ & $\mathrm{PS}$ & $\mathrm{PM}$ & $\mathrm{PB}$ & $\mathrm{PB}$ & $\mathrm{PB}$ \\
$\mathrm{PB}$ & $\mathrm{Z}$ & $\mathrm{PS}$ & $\mathrm{PM}$ & $\mathrm{PB}$ & $\mathrm{PB}$ & $\mathrm{PB}$ & $\mathrm{PB}$ \\
\hline
\end{tabular}


3ph 4w Bal Sin $p-q$ with PI Controller
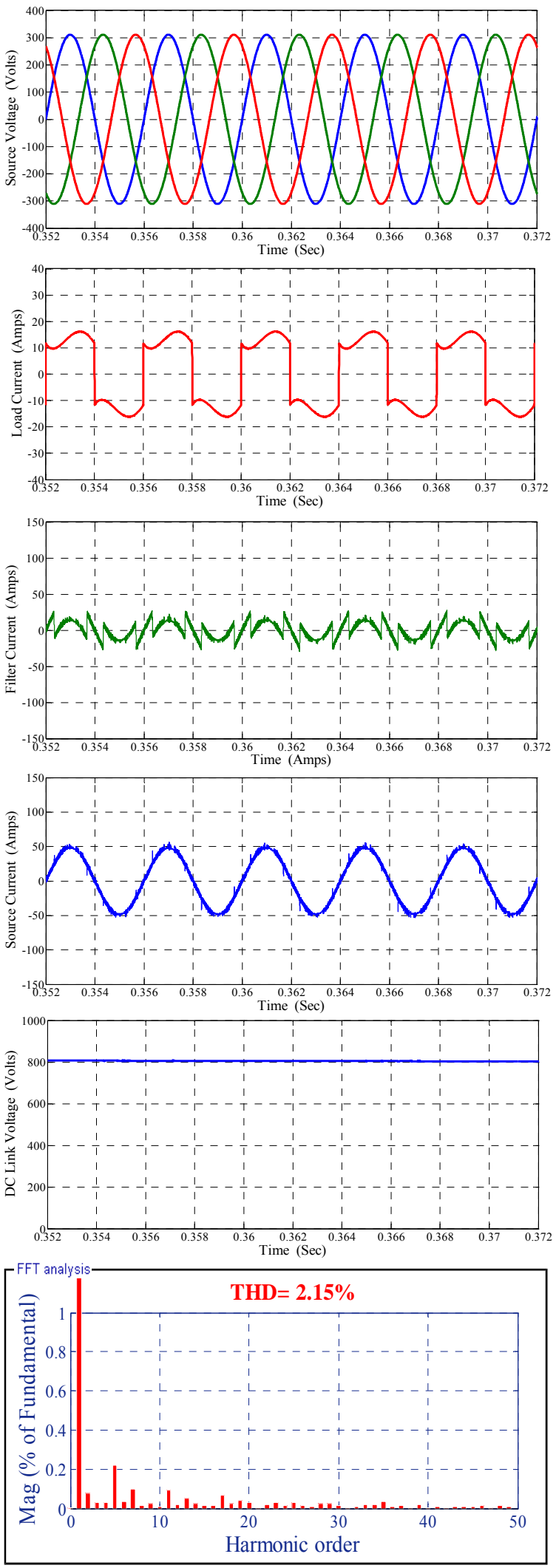

(a) 3ph 4w Bal Sin $p-q$ with Fuzzy Controller
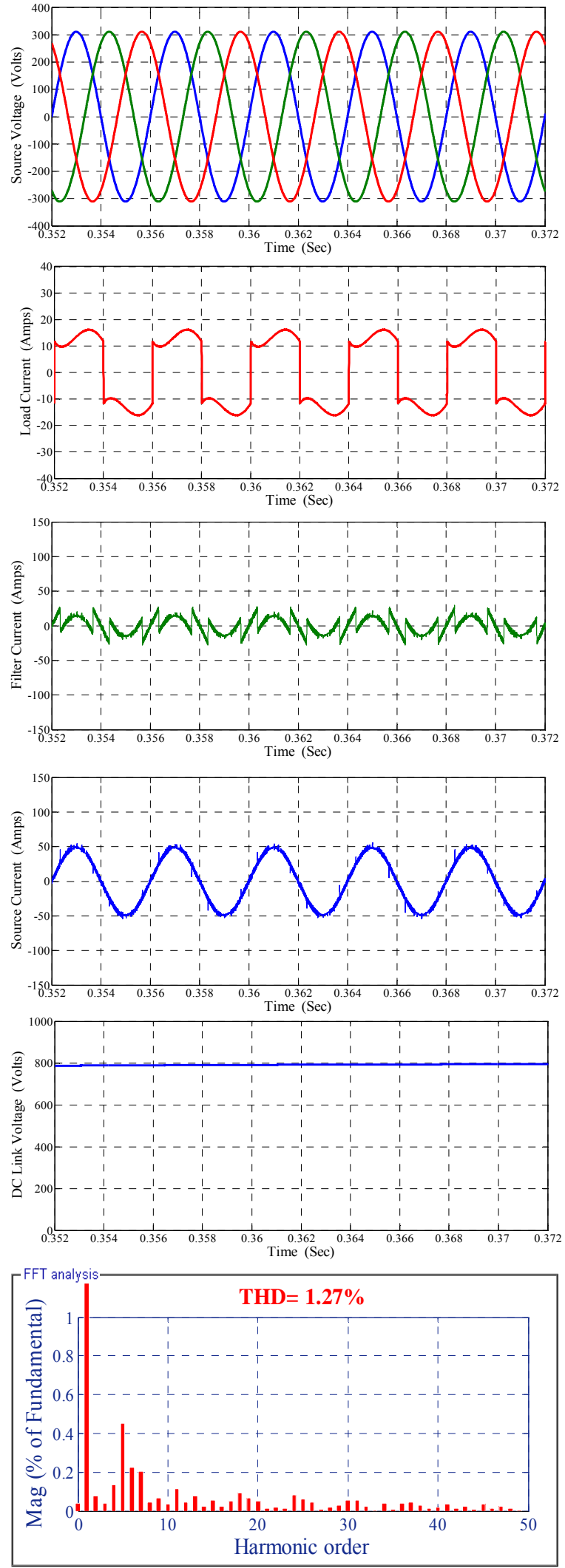

(b) 

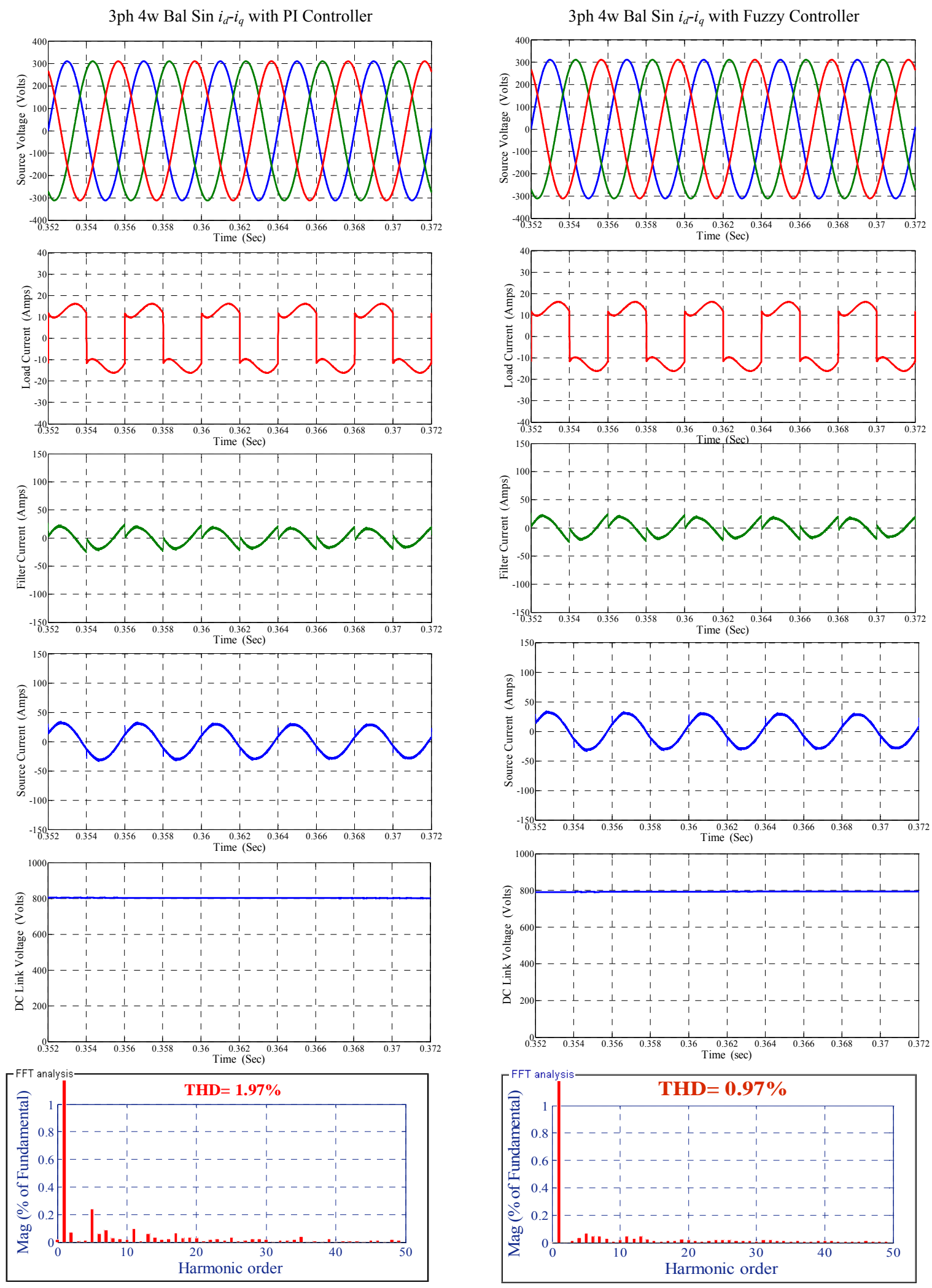

(c)

(d)

Figure 10. Shunt active power filter response under balanced sinusoidal voltage conditions for (a) $p$ - $q$ method with PI; (b) $p$-q method with Fuzzy; (c) $i_{d}-i_{q}$ method with PI; (d) $i_{d}-i_{q}$ method with Fuzzy Controller. 

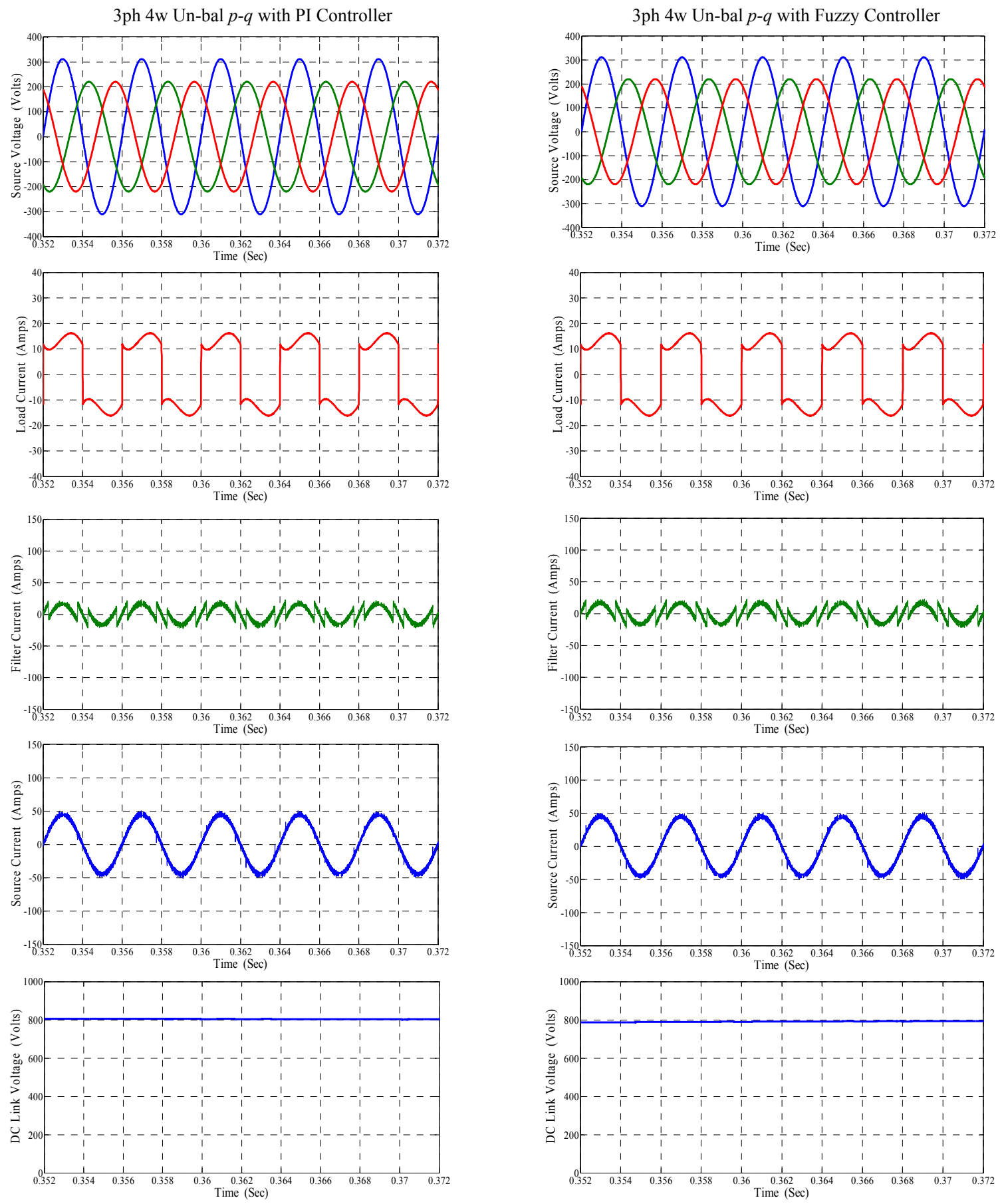

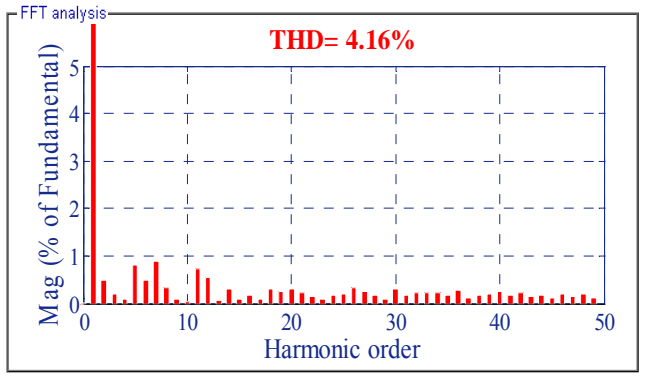

(a)

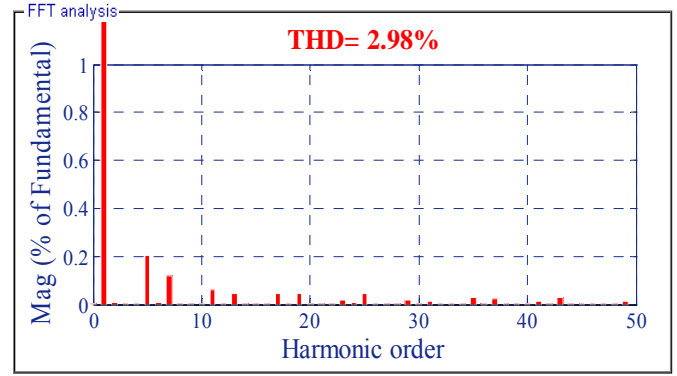

(b) 

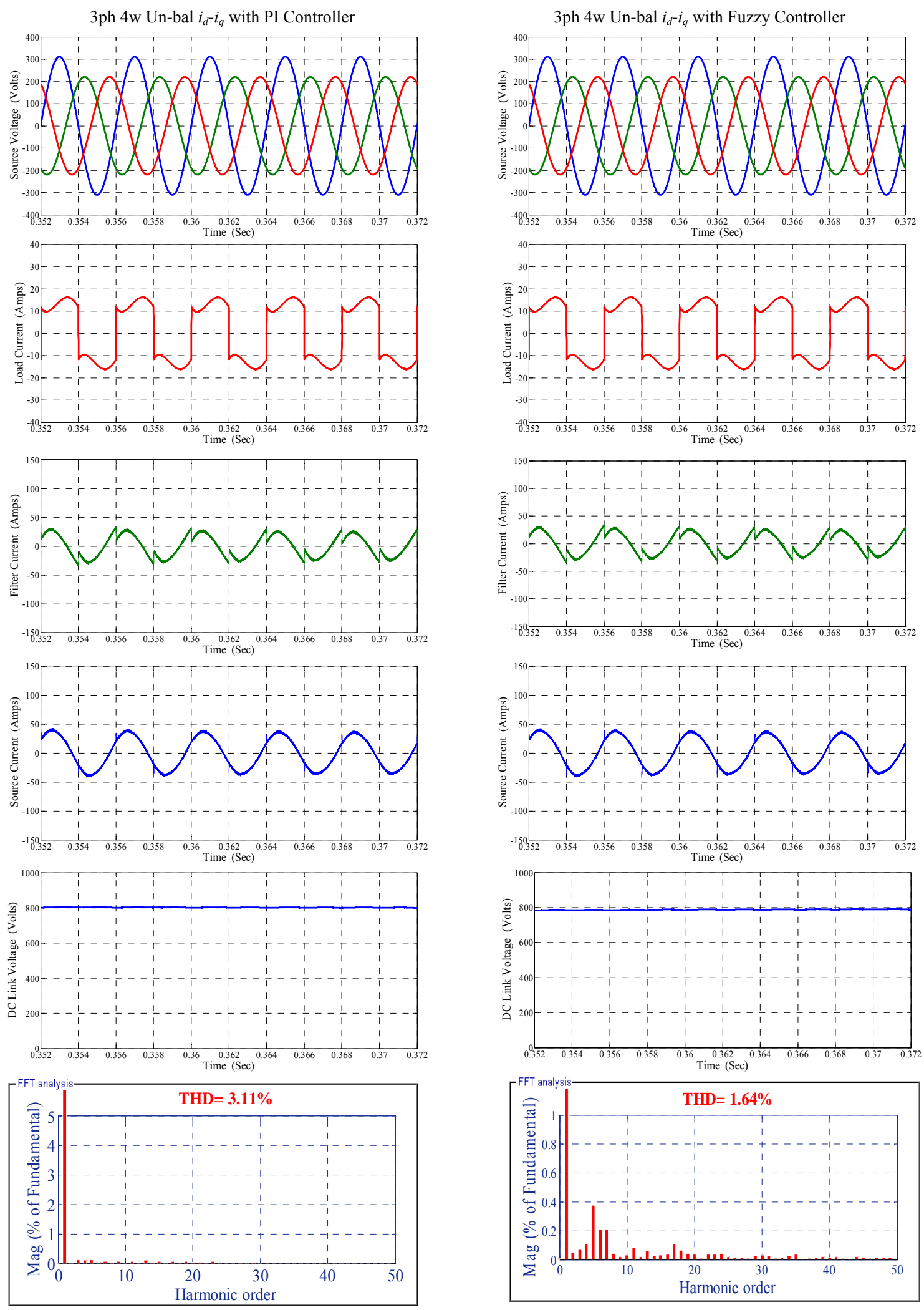

(c)

(d)

Figure 11. Shunt active power filter response under Un-balanced sinusoidal voltage conditions for (a) p-q method with PI; (b) $p$-q method with Fuzzy; (c) $i_{d}-i_{q}$ method with PI; (d) $i_{d}-i_{q}$ method with Fuzzy Controller. 
3ph 4w Non-Sin $p-q$ with PI Controller
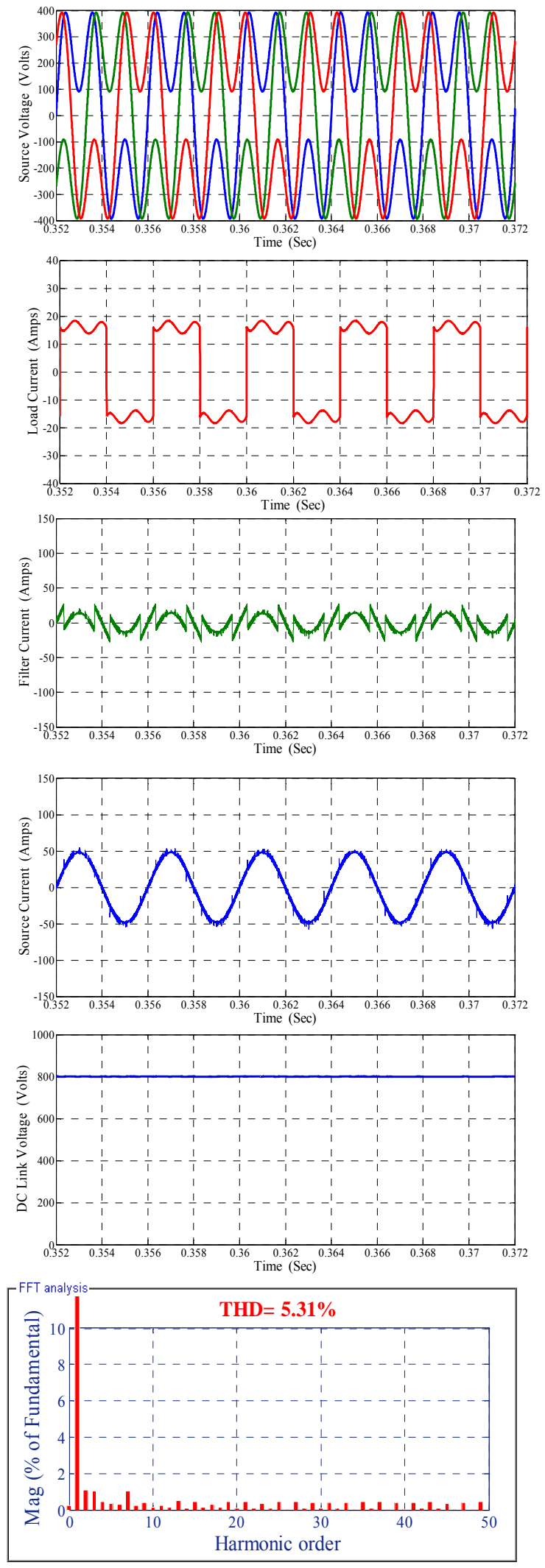

(a) 3ph 4w Non-Sin $p-q$ with Fuzzy Controller
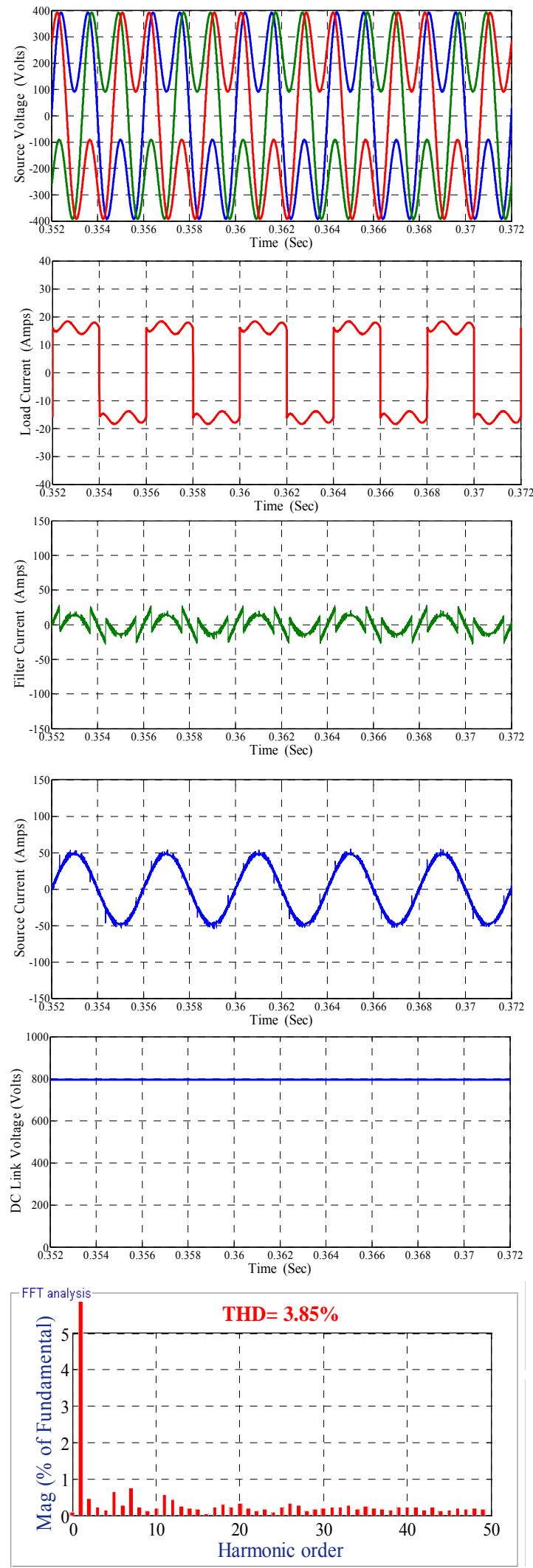

(b) 

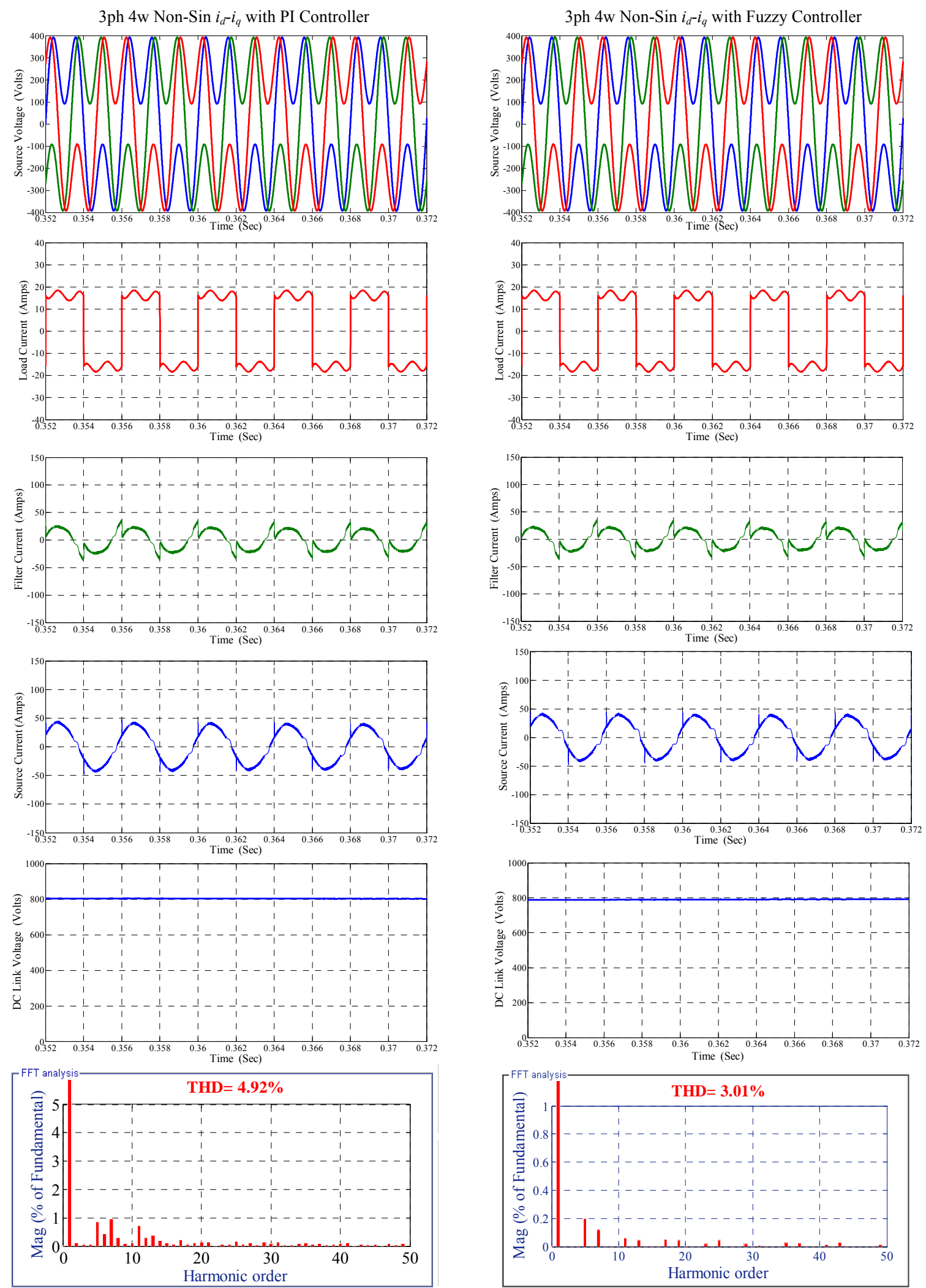

(c)

(d)

Figure 12. Shunt active power filter response under balanced non-sinusoidal voltage conditions for (a) p-q method with PI (b) $p$-q method with Fuzzy; (c) $i_{d}-i_{q}$ method with PI; (d) $i_{d}-i_{q}$ method with Fuzzy Controller. 


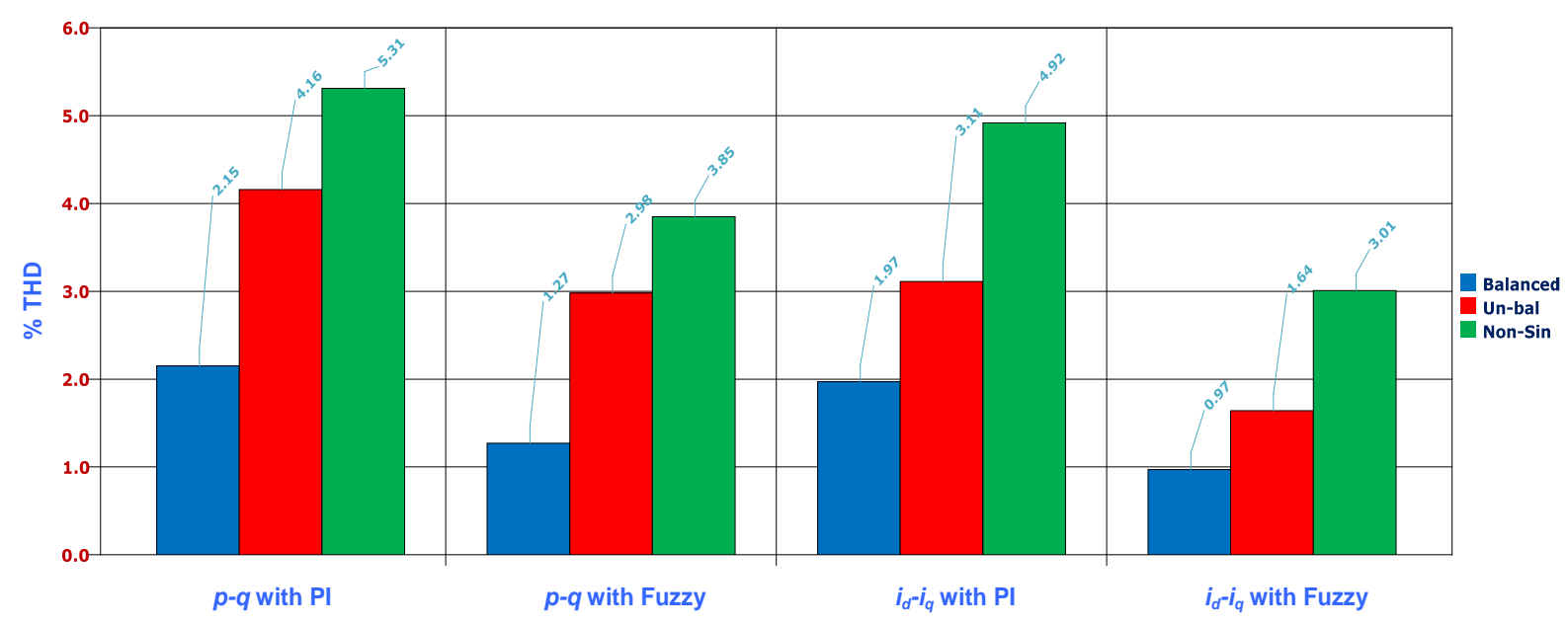

Figure 13. THD for $p-q$ and $i_{d}-i_{q}$ control methods with PI and Fuzzy Controllers.

On observation pi controller fails to respond quickly because of non-linear nature in the system, but fuzzy supports with outstanding performance under any voltage conditions. Frankly fuzzy is finest controller in all the controllers, but it too have some drawbacks like redundancy and iteration problems. So one has to choose the membership function on the bases system complexity. Extensive simulation is carried out to validate both controllers, on over all with combination of $i_{d}-i_{q}$ strategy and fuzzy controller; there is possibility of building novel shunt active filter for 3 phase 4 wire system.

\section{Conclusions}

In the present paper two control strategies; instantaneous real active and reactive power control strategy $(p-q)$ and active and reactive current control strategy $\left(i_{d}-i_{q}\right)$ are developed and verified with three phase four wire system by using two different controllers PI controller as well as fuzzy controller. Though the two strategies are capable to compensate current harmonics in the 3 phase 4-wire system, but it is observed that instantaneous active and reactive current $i_{d}-i_{q}$ control strategy with fuzzy controller lead always better result under balanced, un-balanced and non-sinusoidal voltage conditions over remaining combinations.

On contrast $p-q$ theory needs additional PLL circuit for synchronization so $p-q$ method is frequency variant, where as in $i_{d}-i_{q}$ method angle " $\theta$ " is calculated directly from main voltages and thus enables the method to be frequency independent. Thus large numbers of synchronization problems with un-balanced and non-sinusoidal voltages are also avoided. Addition to that $\mathrm{DC}$ voltage regulation system valid to be a stable and steady-state error free system was obtained.

\section{References}

[1] H. Akagi, "New Trends in Active Filters for Power Conditioning," IEEE Transactions on Industry Applications, Vol. 32, No. 6, 1996, pp. 1312-1322. doi: $10.1109 / 28.556633$

[2] M. Suresh, A. K. Panda and Y. Suresh, "Fuzzy Controller Based 3Phase 4-Wire Shunt Active Filter for Mitigation of Current Harmonics with Combined $p-q$ and $i_{d}-i_{q}$ Control Strategies," Journal of Energy and Power Engineering, Vol. 3, No. 1, 2011, pp. 43-52.

[3] Z. Peng, et al., "Harmonic and Reactive Power Compensation Based on the Generalized Instantaneous Reactive Power Theory for Three-Phase Four-Wire Systems," IEEE Transactions on Power Electronics, Vol. 13, No. 5, 1998, pp. 1174-1181. doi:10.1109/63.728344

[4] V. Soares, et al., "Active Power Filter Control Circuit Based on the Instantaneous Active and Reactive Current $I_{d}-I_{q}$ Method," IEEE Power Electronics Specialists Conference, Vol. 2, 1997, pp. 1096-1101.

[5] S. Mikkili and A. K. Panda, "Simulation and RTDS Hardware Implementation of SHAF for Mitigation of Current Harmonics with $p-q$ and $i_{d}-i_{q}$ Control Strategies Using PI Controller," International Journal of Engineering, Technology \& Applied Science Research, Vol. 1, No. 3, 2011, pp. 54-62.

[6] S. Mikkili, A. K. Panda and S. Yellasiri, "RTDS Hardware Implementation and Simulation of 3-ph 4-Wire SHAF for Mitigation of Current Harmonics Using $p-q$ Control Strategy With Fuzzy Controller," Journal of Power Electronics \& Power Systems, Vol. 1, No. 1, 2011, pp. 13-23.

[7] H. Akagi, H. Kanazawa and Y. Nabae, "Instantaneous Reactive Power Compensators Comprising Switching Devices without Energy Storage Components," IEEE Transactions on Industry Applications, Vol. IA-20, No. 3, 1984, pp. 625-630. doi:10.1109/TIA.1984.4504460

[8] M. I. M. Montero, et al., "Comparison of Control Strategies for Shunt Active Power Filters in Three-Phase Four- 
Wire Systems," IEEE Transactions on Power Electronics, Vol. 22, No. 1, 2007, pp. 229-236.

doi:10.1109/TPEL.2006.886616

[9] H. Akagi, et al., "Instantaneous Power Theory and Applications to Power Conditioning," John Wiley \& Sons, Hoboken, 2007.

[10] M. Aredes, et al., "Three-Phase Four-Wire Shunt Active Filter Control Strategies," IEEE Transactions on Power Electronics, Vol. 12, No. 2, 1997, pp. 311-318. doi: $10.1109 / 63.558748$

[11] P. Rodriguez, et al., "Current Harmonics Cancellation in Three-Phase Four-Wire Systems by Using a Four-Branch Star Filtering Topology," IEEE Transactions on Power Electronics, Vol. 24, No. 8, 2009, pp. 1939-1950.
doi:10.1109/TPEL.2009.2017810

[12] S. Mikkili and A. K. Panda, "APF for Mitigation of Current Harmonics with $p-q$ and $i_{d}-i_{q}$ Control Strategies Using PI Controller," Journal of Trends in Electrical Engineering, Vol. 1, No. 1, 2011, pp. 1-11.

[13] P. Kirawanich and R. M. O'Connell, "Fuzzy Logic Control of an Active Power Line Conditioner," IEEE Transactions on Power Electronics, Vol. 19, No. 6. 2004, pp. 1574-1585. doi:10.1109/TPEL.2004.836631

[14] S. K. Jain, et al., "Fuzzy Logic Controlled Shunt Active Power Filter for Power Quality Improvement," IEEE Proceedings of Electric Power Applications, Vol. 149, No. 5, 2002, pp. 317-328. doi:10.1049/ip-epa:20020511 